\title{
Network-risk: an open GIS toolbox for estimating the implications of transportation network damage due to natural hazards, tested for Bucharest, Romania
}

\author{
Dragos Toma-Danila $^{1}$, Iuliana Armas ${ }^{2}$, and Alexandru Tiganescu ${ }^{1}$ \\ ${ }^{1}$ National Institute for Earth Physics, Măgurele, Ilfov, 077125, Romania \\ ${ }^{2}$ Faculty of Geography, University of Bucharest, Bucharest, 010041, Romania
}

Correspondence: Dragos Toma-Danila (toma@infp.ro)

Received: 12 December 2019 - Discussion started: 8 January 2020

Revised: 1 April 2020 - Accepted: 24 April 2020 - Published: 23 May 2020

\begin{abstract}
Due to their widespread and continuous expansion, transportation networks are considerably exposed to natural hazards such as earthquakes, floods, landslides or hurricanes. The vulnerability of specific segments and structures among bridges, tunnels, pumps or storage tanks can translate not only into direct losses but also into significant indirect losses at the systemic level. Cascading effects such as post-event traffic congestion, building debris or tsunamis can contribute to an even greater level of risk. To support the effort of modeling the natural hazards' implications at the full transportation network scale, we developed a new applicable framework, relying on (i) GIS to define, analyze and represent transportation networks; (ii) methods for determining the probability of network segments to fail due to natural-hazard effects; (iii) Monte Carlo simulation for multiple scenario generation; (iv) methods to analyze the implications of connectivity loss on emergency intervention times and transit disruption; and (v) correlations with other vulnerability and risk indicators. Currently, the framework is integrated into ArcGIS Desktop as a toolbox entitled "Networkrisk", which makes use of the ModelBuilder functions and is free to download and modify. Network-risk is an attempt to bring together interdisciplinary research with the goal of creating an automated solution to deliver insights on how a transportation network can be affected by natural hazards, directly and indirectly, assisting in risk evaluation and mitigation planning. In this article we present and test Network-risk at the full urban scale for the road network of Bucharest. This city is one of Europe's most exposed capitals to earthquakes, with high seismic-hazard values and a vulnerable building
\end{abstract}

stock but also significant traffic congestion problems not yet accounted for in risk analyses and risk reduction strategies.

\section{Introduction}

The complexity and exposure of our society to natural hazards have significantly increased in the last decades $(\mathrm{Gu}$, 2019; Pesaresi et al., 2017; Fleischhauer, 2008) and will continue to do so. Transportation networks are one of the fundamental pillars of development and support for countries, whether they consist of roads, railways, pipelines, communication lines, maritime, or aerial or other types of networks. Transportation networks are a requirement for almost every inhabited place - residential, commercial or industrial and they continue to be upgraded per location and also expand. As such, they become more and more exposed, if not also more vulnerable. In Recent large-scale natural-hazard events, such as earthquakes (Italy in 2016 and 2009, Nepal in 2015, Haiti in 2010, China in 2008, etc.), some accompanied by very destructive tsunamis (Japan in 2011 or Indonesia in 2018 and 2004), hurricanes and typhoons (Mozambique in 2019, Puerto Rico in 2017, Philippines in 2013 and 2012, Myanmar in 2008, or the USA in 2005), or heatwaves (constant in the last years in countries such as the USA, Australia, Greece or Spain), proved that transportation networks are extremely vulnerable but also vital immediately after the event occurrence. Directly contributing to the economic loss balance of such events, transportation networks are more and more significant, especially in developed coun- 
tries (Wilkerson, 2016). Taking into account also the indirect losses (hard to quantify), it is even more obvious that their vulnerability needs to be reduced.

The functionality of transportation networks is very important both immediately after a hazardous event - constituting support for emergency intervention - and for long time afterwards - in the recovery and prevention phases. Damage to networks can carry direct risks, such as the collapse of vehicles or trains, fire outbreaks, etc. Still, functionality and redundancy are essential in order to ensure that socioeconomic losses do not increase significantly. In any transportation network analysis, the interconnectivity between systems and with other networks should also be considered. In the post-disaster reaction phase, especially road networks prove to be very important (Jenelius and Mattsson, 2015), since they link almost all destinations; in some cases other transportation networks can be also relevant, namely railways, maritime or aerial networks. Communication networks are critical in all disaster cycle phases. Utilities are important for a faster recovery and overall, for ensuring resilience. Previous experiences show that transportation networks are mostly affected by natural disasters in two ways:

- directly - by the collapse of critical components such as bridges, tunnels, storage tanks, pumps, etc.; cracks in roadways due to ground motion effects (settlement, liquefaction); railway displacement; and pipe cracks;

- indirectly - by road blockage due to collapsed buildings (especially in urban areas); blockage due to triggered landslides, flooding or tsunamis; blockage due to traffic congestion generated by post-disaster behavior; emergency-imposed restrictions, etc.

For studying the impact of natural disasters on transportation networks, multi- and inter-disciplinary approaches are needed, combining methods belonging to geosciences, engineering, sociology, economy or informatics. Also, multiple perspectives need to be considered (Franchin et al., 2011):

- temporal perspectives (the disaster management cycle);

- spatial perspectives - local (structural element studies), regional, national, or multinational;

- actors involved (level of management).

In the last 2 decades, significant progress has been achieved in transportation network vulnerability and risk analysis not just at the structural level but also at the functional level. For a comprehensive review, we recommend the studies of Jenelius and Mattsson (2015), Miller (2014), Tesfamariam and Goda (2013), Franchin et al. (2011) in the framework of the Syner-G Project, or Kiremidjian et al. (2007). These studies reveal that the fundamental steps in evaluating the seismic risk of transportation networks are as follows.
- The proper definition of the network, with detailed data regarding component characteristics and connectivity. One of the problems is still, in most cases, the lack of official data: in developed countries there can be available good and updated GIS databases; however in most other countries transportation network data (at least for roads or railways) is not well officially defined and/or shared with the general public, and therefore alternative datasources need to be used, such as OpenStreetMap (opensource), Google Maps, HERE Maps, etc. There are currently many software solutions capable of network development (including AutoCAD Civil 3D, OpenRoads or ESurvey Road Network), but not so many have risk analysis capabilities; among them, we mention popular solutions such as ArcGIS Desktop with the Network Analyst extension, PTV Visum and Vissim, MAEviz and EQvis, or STREET.

- The determination of direct damage probability of individual components. For this, earthquake engineering analysis methods are mostly used, such as dynamic elastic and inelastic analysis using grids and numerical methods: the finite-element method, pushover or timehistory analysis, response spectra, etc. A good synthesis of these methods can be found in Crowley et al. (2011) and Costa (2003).

- The need to define relevant performance indicators, reflecting time or cost differences between pre-and postdisaster network behavior. Many performance indicators for networks can be found in literature, some of the most common at the system level being driver delay, simple or weighted connectivity loss (Pinto et al., 2012; Poljanšek et al., 2011), the system serviceability index (Wang et al., 2010), or the serviceability ratio (Adachi and Ellingwood, 2008).

In recent years, new technologies such as Internet-of-things devices, big data, remote sensing, drones, low-cost sensors and machine learning started to be quickly adopted, as they can provide practical solutions for transportation network data collection and analysis. It is expected that the impact of future natural hazards on transportation networks will be much better recorded (as shown by Voumard et al., 2018), allowing for a better validation of risk models and opportunities to create more representative methodologies for the analysis of network risk, also in near-real time.

In order to analyze systemic risk (and not only component risk), networks need to be evaluated from the perspective of the direct damage implication on connectivity, traffic changes or new traffic flows created, leading to indirect damage. Recent studies have addressed these aspects (Koks et al., 2019; Vodak et al., 2015; Caiado et al., 2012; Bono and Gutierrez, 2011; Douglas et al., 2007; Franchin et al., 2006), going beyond the simple summarization of direct effects and eventually of reconstruction costs generated. These studies 
also highlight an important aspect to consider (Pitilakis and Kakderi, 2011) interactions between the components of the system (inter-interactions) and with components of other systems (intra-interactions).

After analyzing available methodologies and solutions in the field of study, we reached the conclusion that, nowadays, capabilities can be better exploited, enabling not only a more flexible but also a standardized analysis of transportation network implications due to natural hazards compared to previous works. We consider that much has been done theoretically, and too little has been done practically (at least at full city-scale analysis), also leaving room for new technologies, and this is what motivated us to create a new GIS solution sharable with the community and applicable worldwide. In this paper, which provides a settled methodology after preliminary studies such as Toma-Danila (2018) or Toma-Danila et al. (2016), we will focus on the following:

- presenting a methodology for evaluating direct and indirect transportation network risk due to natural hazards, embedded in the ArcGIS Desktop as an open-source toolbox called "Network-risk",

- demonstrating its capabilities for a representative case study - Bucharest - one of the most vulnerable capitals in Europe due to the implications of earthquakes, where results represent an important contribution to emergency management risk reduction planning.

\section{Methodology and implementation}

The generalized steps of the methodology are comprised of the following:

- defining a transportation network in a GIS,

- evaluating which segments could be affected by a natural hazard (directly or indirectly) - accounting also for the probability of damage,

- generating random damaged network scenarios based on this probability,

- evaluating the implications in terms of connectivity and serviceability losses and then socioeconomic consequences.

This concept was previously defined in studies such as Hackl et al. (2018), Zanini et al. (2017), Vodak et al. (2015), Chang et al. (2012) or Argyroudis et al. (2005). However, the way each of the tasks are treated, linked and implemented in GIS is what we consider to be progress toward standardization and usability in real situations (also in near-real time). The methodology presented in Fig. 1 allows, among others, the consideration of multiple transportation network types (road, railway, utilities, etc., represented at the local, regional or national level) and of different natural hazards. The methodology can accommodate, for example, the analysis of earthquake implications, where damage is widespread, and building debris, traffic patterns and a good level of detail for network definition are necessary to be considered. For landslides, the factors to be considered will change, since damage will be much more punctual and random simulations might not be so representative. For flooding, vulnerability analysis of networks such as road or railways will require knowledge on topography - not so representative of earthquake analysis. Still, the methodology will accommodate all these hazard types and influences, as long as, for example, loss analysis will lead to the identification of possibly affected network segments. There is also flexibility in the way the risk analysis is oriented - toward emergency intervention, economic losses evaluation or urban planning.

Most of the input data (yellow boxes in Fig. 1) are required, also with GIS reference, with the exception that, depending on the analysis type, emergency intervention facilities or origin-destination (OD) pairs will not necessary be needed. In addition, an analysis without typical traffic data can be performed, although it might be representative just for night traffic conditions.

The process of building a consistent transportation network, from more or less complex datasets, is an essential part of every network analysis. To assist in this effort we created a guide, models and layer symbology for properly converting and editing data partially manually, following also the ArcGIS Desktop Network Analyst extension recommendations. An alternative solution can be to use the ArcGIS OpenStreetMap (OSM) editor (https://github.com/ Esri/arcgis-osm-editor, last access: 27 April 2020) for OpenStreetMap data (it is possible, however, to experience limitations in expressing $Z$ elevation), GRASS GIS v.net or procedures such as those in Karduni et al. (2016). Eventually, the converted data are expected by Network-risk to be similar to the sample files provided on the Network-risk web page. At the moment, the compulsory columns required in the analysis are "name", "oneway", "F_ZLEV”, "T_ZLEV”, "hierarchy", "maximum_speed", "FT_minutes" and "TF_minutes". To these, further columns accounting for traffic, scenario travel times or lack of functionality due to natural-hazard effects will be added, depending on data availability and analysis type. In the process of defining the rules for the network dataset (ND), the Network-risk toolbox requires adding more evaluators besides the ArcGIS Network Analyst extension defaults, with the most important being for obstructions (used in service area analysis in the impedance field to reveal inaccessible road areas) and others for different typical traffic scenarios or for economic costs.

Both pre- and post-earthquake traffic data are highly important, since they show the typical functionality status of the network and the premises for new traffic congestion immediately after an earthquake (with correlations also to road 


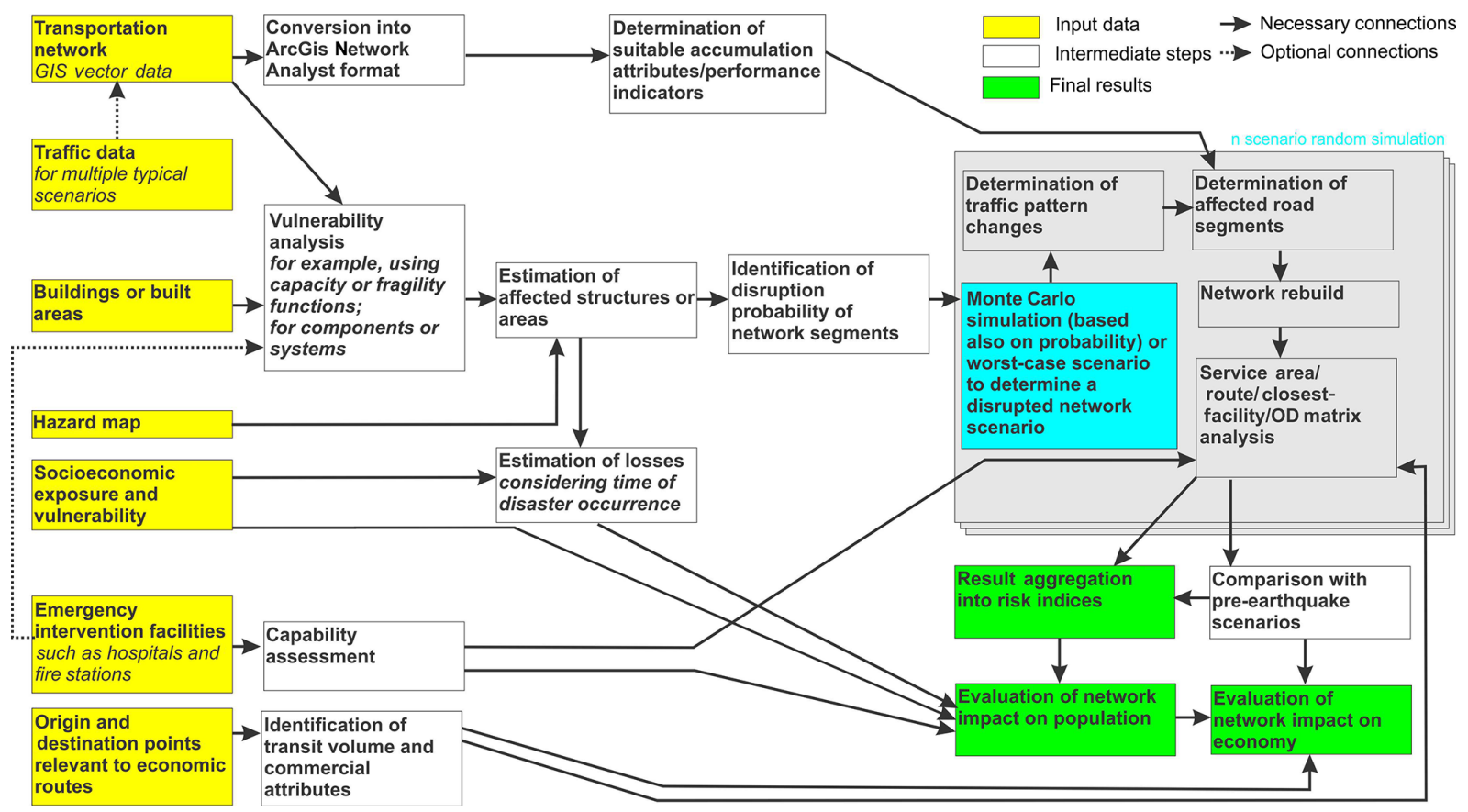

Figure 1. Graphical representation of the proposed methodology for evaluating the implications of transportation network damage due to natural hazards, integrated into the Network-risk toolbox.

segments blocked by, for example, building debris or bridge collapse). Typical traffic data can be retrieved from local datasources (such as traffic management authorities) or from companies taking advantage of new device capabilities, such as Google Traffic, HERE Traffic or Waze. These sources provide live (or statistical) data regarding traffic values and reported incidents, although to integrate these data into our framework, it is needed to convert these data into travel speed per road segment or to turn to barrier or restriction GIS layers. Other solutions with near-real-time analysis capabilities can be to use GPS data - from emergency vehicles or the expertise of their drivers - especially for emergency management analysis.

The network layer represents the exposure; to evaluate the vulnerability of network segments to a specific natural hazard (or multiple hazards - the analysis can also take this dimension), it is required to associate failure probabilities. For individual structures (such as bridges, tunnels, pump facilities, electricity poles) or for buildings (including network buildings), vulnerability functions are commonly used to determine damage probability or even more: functionality loss or resilience functions such as closure time or recovery cost. Although it is recommended to use structure-specific (local) functions, considering particular properties of the structure and of the construction practices in the specific country or region, there are currently available fragility function libraries, collected and harmonized in projects such as Hazus, Syner-G or SERA, which can be associated, preliminarily, with some of the assets in other region. In some cases, analyzing the probability of a building to collapse can be further linked to the probability of road blockage, due to debris, for example (in the case of earthquakes, there are equations for this purpose, such as those of Santarelli et al., 2018; Zanini et al., 2017; Argyroudis et al., 2005; and Moroux et al., 2004). Knowing where affected areas are also contributes to the evaluation of indirect risk, aiding, for example, the calculation of the chance of people caught under debris to survive, using results of field studies such as those of Hekimoglu et al. (2013), Coburn and Spence (2002), or Goncharov (1997).

After including references to the natural hazard, in the form of maps with transferable values to vulnerability functions, the result would be an evaluation of the direct possible damage and, as such, a probability of network segment blockage. This can be used for generating random scenario simulations using the Monte Carlo approach (potential acknowledged by Burt and Graham, 1971) in order to test the behavior of the network in multiple probable situations. Assigning a probability of $100 \%$ for the failure of a network segment (indicating certain blockage) is useful for worstcase scenarios or clear cases of vulnerability (for example, a highly vulnerable bridge which will certainly not withstand high acceleration values due to an earthquake or a road segment where rockfalls happen even without a significant trigger). However, in most of the cases this probability will need to be smaller, allowing for random simulations to show multiple implication patterns. Also, post-disaster traffic can be considered independently for each simulation. Monte Carlo scenarios are usually supposed to come in large numbers 
(hundreds or thousands of runs), and, depending on the size of the network, the amount of computational time is expected to be considerable. However, the need for a vast number of Monte Carlo scenarios might not really be necessary. The existence of many viable detour routes in urban areas or the small number of identified network segments expected to be highly damaged can determine the need of a smaller sample of Monte Carlo scenarios - this is why the stabilization of results must be traced.

For estimating post-event traffic patterns, assumptions providing travel speed modifications for road segments located close to affected areas, especially in urban agglomerations, must be included. Some hints for determining these patterns can be found in the work of Zanini et al. (2017) or Chang et al. (2012). More complex approaches relying on individual driver behavior simulations or decision patterns, as described in Asaithambi and Basheer (2017) or Munigety and Mathew (2016), can be implemented.

At the core of the network implication analysis, different shortest-path routing algorithms (by short, not referring always to distance but also to less risk) can be used, such as the Dijkstra algorithm, the $A^{*}$ algorithm, Johnson's algorithm or the Floyd-Warshall algorithm. In our implementation and case study we preferred the Dijkstra algorithm, which was used for computing the shortest distance (in real meters or costs) for various network configurations - pre- and postevent (for service area, route, closest facility or OD matrix analysis). This algorithm is widely used in systemic network analysis (Sniedovich, 2016), providing a good balance between precision and performance (Bast et al., 2016) and being also chosen as a preloaded algorithm in ArcGIS. Depending on user preferences, other algorithms can be applied - using, for example, an alternate approach relying on QGIS with pgRouting (https://pgrouting.org/, last access: 27 April 2020) or $A^{*}$ in ArcGis. For service area analysis, used in the emergency intervention travel time evaluation, we recommended, as an analysis method, using detailed polygon generation, with results of prior analysis for identifying inaccessible network areas as barriers, since the results will better reflect small inaccessible areas.

The entire methodology is embedded in a toolbox called Network-risk, which currently runs under ArcGIS Desktop Advanced (10.1+ version) with the Network Analyst extension enabled, using ModelBuilder capabilities (Fig. 2). This toolbox takes advantage of the geo-processing already available and location-allocation algorithms and enables a standardized, non-hazard dependent and automated large-scale network risk analysis. In this direction, we acknowledge the previous works of Vodak et al. (2015), Pinto et al. (2012), or Sevtsuk and Mekonnen (2012), which we consider, however, not fully usable, especially in the more recent context. Having the methodology implemented in ArcGIS offers extended analysis support through cartographic, spatial analyst modules, available basemaps, plug-ins such as ArcCASPER (Shahabi and Wilson, 2014) for computing evacuation routes and others. We chose to split Network-risk into multiple separate modules (such as for network creation, Monte Carlo scenario creation, disrupted network building, service area analysis or aggregation of results into a final index), making it easy to identify errors at different steps. The toolbox is available for download at http://www.infp.ro/index.php?i= nri (last access: 27 April 2020) and is free to use and customize.

Considering the steps described in Fig. 2, ArcGIS Network Analyst capabilities and the results which are later shown by our case study, the Network-risk toolbox is capable of answering important questions for emergency management, city planning, commercial, insurance, industrial or real-estate agents and many others, such as the following:

- Which areas could become inaccessible after a natural disaster? What are the vital access routes in case of a disaster? Are there viable detour routes?

- What is the socioeconomic impact (in terms of human or financial losses) in case of a natural disaster, correlated also with emergency management capabilities?

- How would new network segments, hospitals, fire stations or other facilities contribute to reducing the risk? Where should they be placed?

\section{Bucharest road network case study, considering seismic hazard}

\subsection{Case study area description}

For testing the methodology, we selected Bucharest - one of Europe's endangered capitals due to high seismic risk (TomaDanila and Armas, 2017; Pavel, 2016). The city was previously affected by strong earthquakes in the Vrancea seismic area (such as the ones on 10 November $1940, M_{\mathrm{w}}=$ 7.7 , at $150 \mathrm{~km}$ depth, and on 4 March $1977, M_{\mathrm{w}}=7.4$, at $94 \mathrm{~km}$ depth) and is currently still poorly prepared (Pavel, 2016) for the next major event, which will most certainly happen anytime in the next 100 years. Compared to 1977 (when 1578 people died in Romania, of which 90\% were in Bucharest), the city now faces an additional challenge besides the high vulnerability of the building stock: the vulnerability due to the road network and urban traffic. In a city with over 2 million inhabitants, there are 1.2 million registered vehicles (NIS, 2018). To this number, the contribution of transit vehicles not adequately serviced by an external ring road (Fig. 3c) or vehicles of numerous commuting persons from nearby counties or students can also be added. In the absence of efficient urban development and mobility measures, in combination with mentality issues (the self-requirement to own and use a car), the city faces regular traffic jams, being ranked as Europe's number one capital (5th in the world in 2017 and 11th in 2018) when it comes to the typical congestion level (TomTom, 2018; typical traffic examples in 


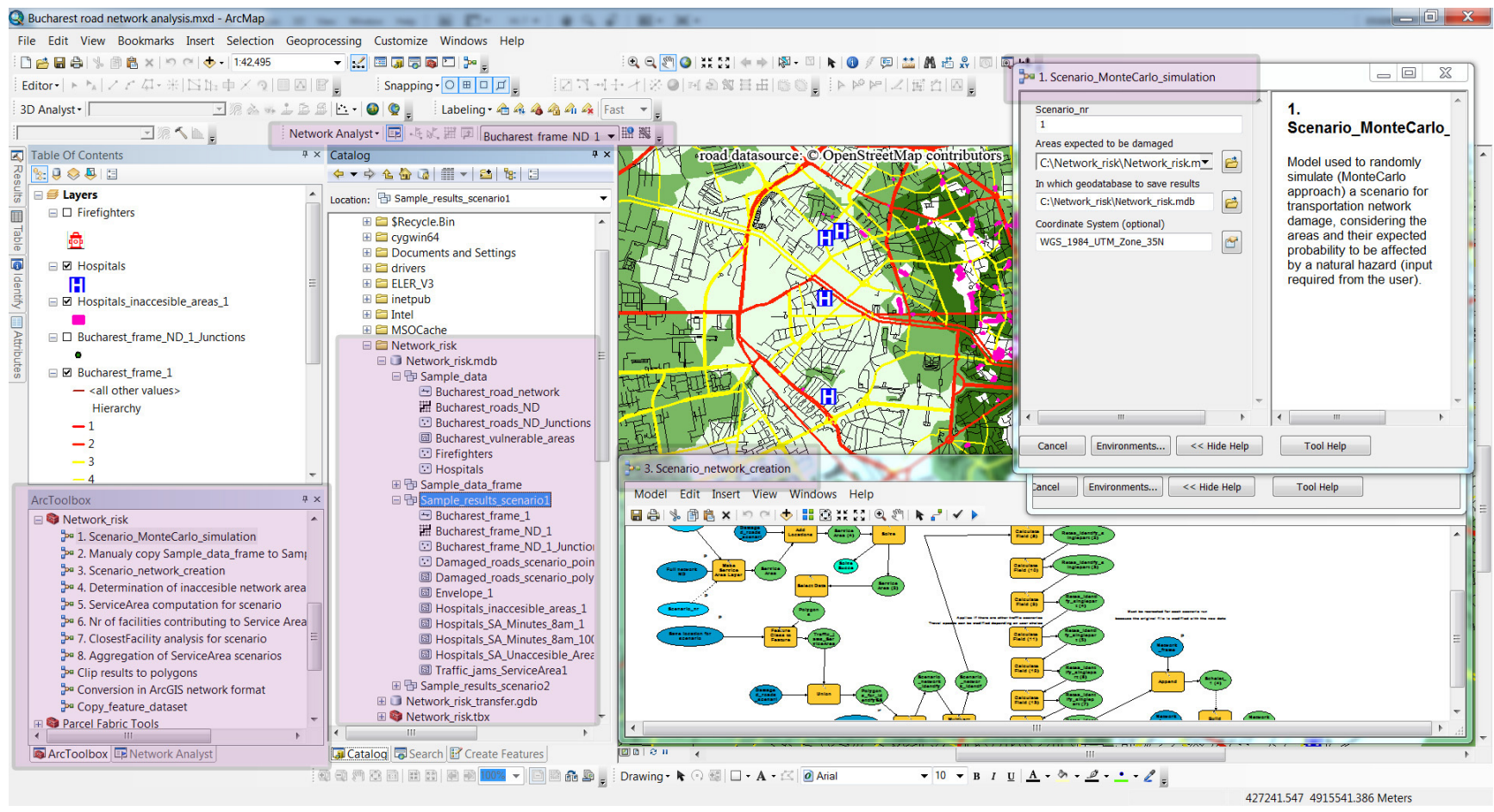

Figure 2. Screen capture of ArcGIS Desktop ArcMap with Network-risk toolbox added, contributing to the analysis of Bucharest's road network risk analysis; the framework of one of the models (3. Scenario_network_creation) can be seen as well as the model run interface (1. Scenario_MonteCarlo_simulation), the Network-risk toolbox modules and the sample data results created using these modules (highlighted in purple).

Fig. 3d-f). Beside traffic, Bucharest's road network maintenance and serviceability status is precarious, with much dysfunction related to the quality of embankments, bridges, or over- or underpasses (Fig. 3a); poor construction and maintenance; and limitations in the full utilization of roads' size due to illegal (and unsanctioned) parking in many cases (Fig. 3b) or constantly exceeded deadlines for repair or new roadwork. Another important aspect is that many buildings, not solely in the city center, are highly vulnerable to earthquakes (TomaDanila et al., 2017). More than 31430 residential buildings were constructed prior to 1946 (294 having more than four stories - a vulnerable category due to long fundamental periods of intermediate-depth Vrancea earthquakes), according to the 2011 National Population and Housing Census. In addition, 26349 residential buildings ( 237 having more than four stories) were constructed between 1946 and 1960, a period with no compulsory seismic design code, having endured at least one major earthquake with limited evaluation and seismic retrofitting afterwards (Georgescu and Pomonis, 2018). One should realize that if only $1 \%$ of the buildings completely or partially collapse, it could clearly lead to many deaths and injuries, which are difficult to manage not only due to hospital capacity and equipment, as the recent Colectiv Club fire disaster proved (Marica, 2017), but also due to severe road blockages. In 1977, central boulevards such as Magheru were closed for at least $3 \mathrm{~d}$ after the 4 March earth- quake; still the typical traffic was not severely affected due to low traffic values and the wide use of public transport in those days. We believe that nowadays, such a measure would have much more adverse implications. Considering also the much larger expected damage scale nowadays (Armas et al., 2016; Pavel and Vacareanu, 2016), emergency intervention will have to be provided from multiple locations (inside and outside of the city), and usual traffic patterns (not to mention the ones right after a major earthquake, depending also on the time of occurrence) will clearly act against a proper reaction. All these problems make Bucharest a highly representative test bed for the methodology proposed in this article.

Preliminary analysis of the associated seismic risk of the Bucharest road network was performed in recent years, using slightly different approaches (Toma-Danila, 2018; Ianoş et al., 2017); however these were not so flexible or were not at the full city scale, concentrating only on the city center. Our goal for the analysis is to play an important role in the mitigation of seismic risk in Bucharest, being the first analysis for the entire city of Bucharest.

\subsection{Data and methods considered for Bucharest}

The starting point for the analysis was the development of a road network GIS database, respecting connectivity and elevation rules. Currently, an official database of this kind is not 


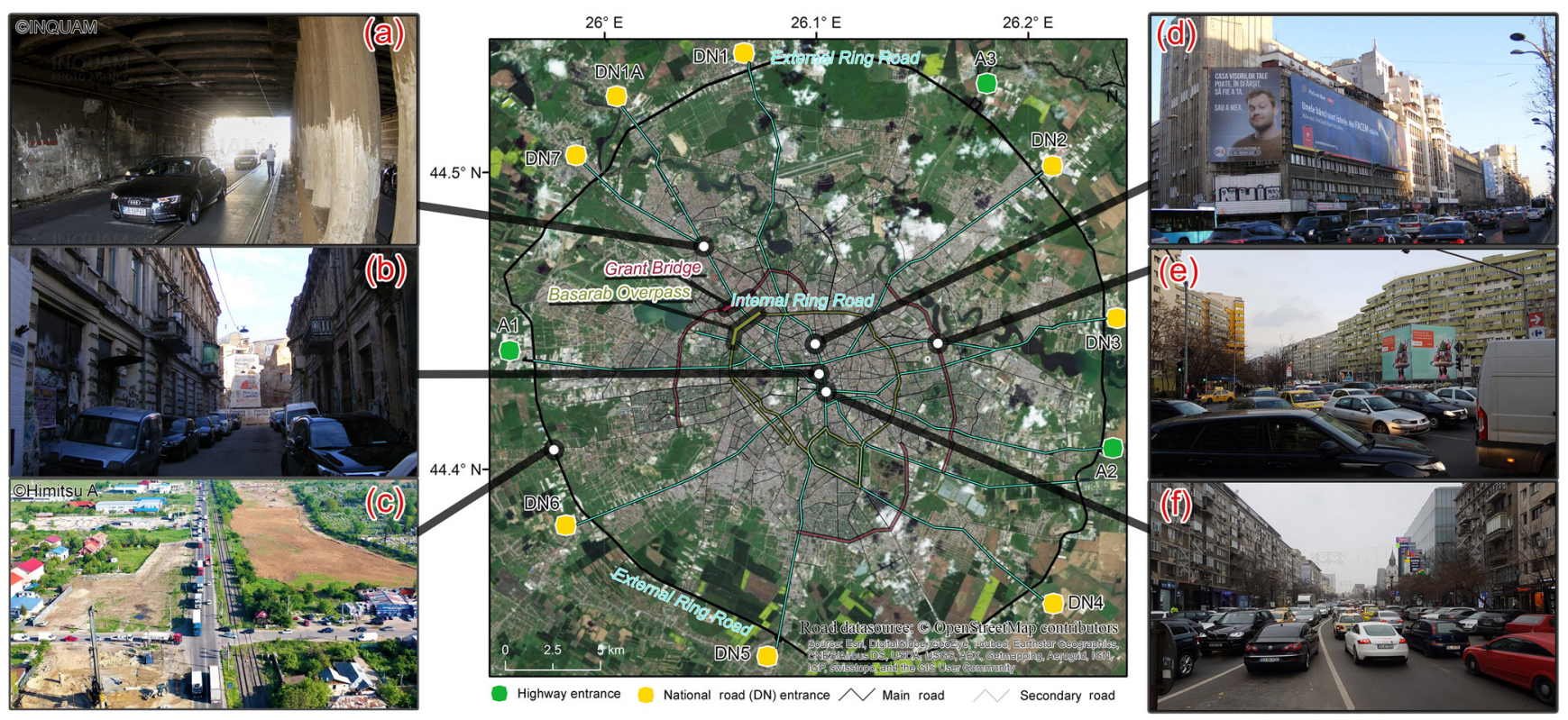

Figure 3. Bucharest road network map, highlighting main roads and connections with highways and national roads. (Datasource: (C) OpenStreetMap contributors 2019. Distributed under a Creative Commons BY-SA License; data from September 2016. Basemap: (C) ESRI and contributors.) Examples of vulnerable area: Constanța Bridge underpass (@ INQUAM) (a), illegal parking (b), southern external ring road dysfunctionalities (c), typical rush-hour traffic (@ Himitsu A.) (d-f) and vulnerability due to old buildings with seismic risk (b, d).

available for Bucharest. This is why we used data from OSM, which is one of the most successful crowdsourcing projects aiming to create a geospatial database of the whole world, with relatively up-to-date data for Romania, thanks also to the involvement of many local volunteers (https://forum. openstreetmap.org/index.php, last access: 27 April 2020), and with good applicability in vehicle routing (Graser et al., 2014). OSM road vector data were downloaded using the Geofabrik GIS Data Portal (http://download.geofabrik.de, last access: 27 April 2020), requiring additional processing in ArcGIS Desktop's ArcMap (Network-risk toolbox template and guidelines are provided) in order to convert it into the ArcGIS network format, accounting for connectivity, hierarchy, travel direction (from-to - FT - and to-from - TF), $Z$ elevation (creating distinctions between roads at ground level, bridges or underpasses) and travel time. For Bucharest - up to the external ring road and its connections to the city center - the final number of individual road segments (everything represented in Fig. 3) was 50412. We used data from September 2016; since then, until December 2019, no major road network modifications have been made in Bucharest (the main exception being the extension of A3 up to northeastern Bucharest, but with no major influence on our analysis). When analyzing statistics (especially road length) it is important to account for road segments' difference of drawing roads per lane or as a whole in OSM - otherwise the real number of kilometers will in some cases be doubled. This is why we prefer not to present statistical road length graphs.
For determining which road segments can be affected by earthquakes, we used the procedures described in Table 1. In total the following values were determined, totaling to $1.41 \%$ of the total number of road segments in Bucharest:

- 1324 segments with variable length which can become affected by debris (partially shown in Fig. 4; just $32.6 \%$, however with a damage probability $>50 \%$ )

- 985 segments with variable length can become directly affected by bridge collapse.

After performing 20 Monte Carlo simulations (each with an average runtime of $12 \mathrm{~min}$ on a normal desktop computer from simulation to service area results), we considered the results to be stable enough to reflect the damage patterns for the rather extended road network of Bucharest and stopped our simulations, which are not time-consuming but still difficult to summarize automatically.

In order to account for traffic - a major issue for Bucharest - we followed the patterns shown typically by Google Traffic for various representative scenarios:

- Monday at 02:00 LT - no traffic,

- Monday at 08:00 LT - morning traffic,

- Monday at 18:00 LT - end-of-work traffic.

Traffic values were obtained by the following procedure:

- digitizing areas described qualitatively in Google Traffic (very slow, slow, moderate or fast traffic), 


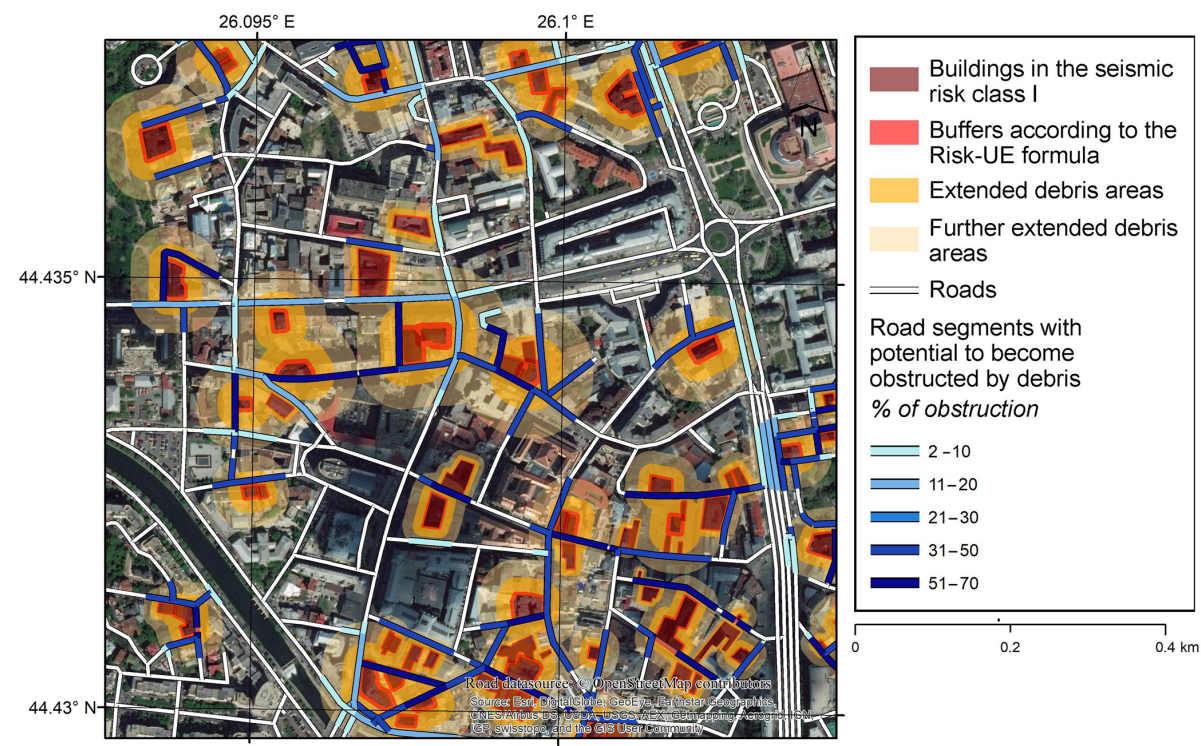

Figure 4. Example of road blockage analysis due to building debris, applied for the historical center of Bucharest. (Datasource: () OpenStreetMap contributors 2019. Distributed under a Creative Commons BY-SA License; data from September 2016. Basemap: (C) ESRI and contributors.)

Table 1. Factors considered for determining the probability of road segments to be affected by earthquakes.

\begin{tabular}{|c|c|}
\hline Factor & Method of analysis \\
\hline Bridges & $\begin{array}{l}\text { Mean fragility functions from Crowley et al. (2011) for the corresponding structural typology (mostly } \\
\text { reinforced concrete) were used. Considering the microzonation map of Marmureanu et al. (2010) for } \\
\text { maximum peak ground acceleration (PGA) values in Bucharest due to the largest probable earthquake } \\
\text { in Vrancea, the complete damage probabilities obtained were small: } 1.5 \%-2 \% \text {. For the Basarab } \\
\text { Overpass, fragility functions were adapted due to different characteristics (suspension and steel-arch } \\
\text { bridge sections, seismic passive dampers), considering descriptions in Sartori (2012). }\end{array}$ \\
\hline \multirow[t]{2}{*}{$\begin{array}{l}\text { Roads blocked } \\
\text { by building } \\
\text { debris }\end{array}$} & $\begin{array}{l}\text { We used Eq. (1) (from Moroux et al., 2004) to determine the probability of roads to be blocked by the } \\
\text { debris generated by the collapse of buildings in the seismic risk class I, which are most likely to collapse } \\
\text { during the design earthquake corresponding to the ultimate limit state ( } 349 \text { in total, mostly with more } \\
\text { than four stories, according to Bucharest City Hall data from January } 2016 \text { - } \\
\text { https://amccrs-pmb.ro/liste-imobile, last access: } 27 \text { April 2020); the footprint of buildings was } \\
\text { determined, and buffers were added according to debris area; the output (Fig. } 4 \text { ) was supplemented by } \\
\text { expert judgment based on satellite images, building structural considerations and building vicinity, road } \\
\text { width etc., to attribute road blockage probabilities - ranging from } 1 \% \text { to } 70 \% \text {, since no building is } \\
\text { certain to collapse. }\end{array}$ \\
\hline & Debris area $(m)=\frac{2}{3} \cdot$ Number of floors \\
\hline Liquefaction & $\begin{array}{l}\text { We attempted to use some data (Neagu et al., 2018), but eventually the liquefaction map was considered } \\
\text { too generic; after more detailed analysis we can integrate it into the analysis. }\end{array}$ \\
\hline
\end{tabular}

- identification of roads in these areas (also considering FT and TF ways),

- modification of travel times (for fast traffic - using the maximum allowed speed - and for very slow traffic $2 \mathrm{~km} \mathrm{~h}^{-1}$ ),

- validation with the Google Traffic Directions service (for representative routes crossing the city),
- corrections applied in areas with a considerable deviation from the expected values.

Although time-consuming, this procedure yielded good results. Given that our analysis focuses on the intervention of emergency vehicles, the influence of traffic lights was neglected (although it can be considered for other analysis purposes), and the travel speed was considered to be $50 \mathrm{~km} \mathrm{~h}^{-1}$ for fast-traffic road segments. For regional and national stud- 
ies, detailed traffic values might not be needed, since many highways or intercity roads (generally not crossing urban areas) do not have typical traffic jams, further impacting the emergency management intervention times. For estimating post-event traffic patterns, we used a simplified approach, based on the following traffic modification parameters:

- for areas closer to $100 \mathrm{~m}$ (calculated on roads as service area not as buffer) $-2 \mathrm{~km} \mathrm{~h}^{-1}$,

- for areas closer to $500 \mathrm{~m}-5 \mathrm{~km} \mathrm{~h}^{-1}$.

This approach has obvious limitations and uncertainties; however, it provides a flexible and easy-to-compute method of accounting for traffic shifts right after an earthquake, following the findings of Zanini et al. (2017). Modeling drivers' individual behavior in traffic, also over time, is the next step which we will integrate in future studies, also trying to create the means for validation (recording the traffic patterns after major earthquakes affecting Bucharest or after local incidents in the area of vulnerable buildings).

In order to enable service area analysis for emergency intervention, hospitals and fire stations were used as facilities. We identified all representative locations in Bucharest and nearby (not including children emergency hospitals; therefore the analysis can be considered relevant for the adult population). Although of high importance, we could not include the current data regarding the capacities of each facility (for example, number of ambulances, hospitals' treatment capacity or fire engine equipment); these can be considered, reflecting limitations or restrictions in the emergency intervention process (for example, the number of addresses that can be reached within an amount of time due to vehicle availability, the number of people that can be transported to and hosted by a hospital, or whether there are vehicles with ladders, necessary for intervention in areas with high-rise buildings). We will address these issues in further studies when more complex data become available; the ArcGIS Network Analyst extension can easily accommodate such information, and also special evaluators can be added.

The main analysis toward risk for Bucharest was represented by service area analysis for emergency management facilities (ambulances for emergency hospitals and fire engines), reflecting the times of intervention right after a major earthquake affecting Bucharest (the ultimate limit of state design earthquake) at three different times for which traffic values are considered. Results check the capabilities to offer intervention within the golden hour of medicine (Lerner and Moscati, 2001) - when emergency treatment is most likely to be successful. We also analyzed the pre- and post-earthquake time differences for representative economic transit routes through closest-facility analysis. The parameters used in the analyses are described in Table 2.

The total number of service area maps resulting for all Monte Carlo scenarios, for service area analysis, is considerably large and not relevant independently (the map-by-map evaluation is more important for checking quality and in order to see the stabilization of result patterns). This is why it is needed a further procedure for aggregating data - as is done with big data. Providing data synthesis that is easier to grasp is very important for stakeholders. For this purpose we developed a procedure based on the following reclassification and aggregation procedure.

a. Service area polygons for post-earthquake scenarios were reclassified according to Table 3 .

b. For each service area polygon with identified number of facilities providing the best and second-best intervention time, determination was based on Eq. (1) of a counter $\left(C_{1}\right)$, reflecting the dependency on a specific facility:

$C_{1}=N_{\mathrm{i}}+0.5 \cdot N_{\mathrm{s}}$,

where $N_{\mathrm{i}}$ is the number of facilities providing the best intervention time, $N_{\mathrm{s}}$ is the number of facilities providing the second-best intervention time, and if the service area polygon $\geq 30 \mathrm{~min}, N_{\mathrm{i}}=0$.

c. An index was determined $\left(V_{\mathrm{i}}\right)$ for each scenario, reflecting the reclassified vulnerability, applied to all polygons, following the considerations in Table 4.

d. A weight overlay was determined of $V_{\mathrm{i}}$ values calculated for emergency hospitals and fire stations, for a specific scenario, applying $25 \%$ (0.25) for emergency hospitals and emergency hospitals in category I of importance (in order to reflect the contribution of truly important hospitals in emergency situations) and $50 \%(0.5)$ for fire stations (in Bucharest it is relevant to have an important weight for fire stations, since they do not provide only equipment for fire extinguishing but also mobile services for emergency, reanimation and extrication, abbreviated as SMURD units), leading to a new final vulnerability index per scenario: $V_{\mathrm{f}}$.

e. Monte Carlo scenario simulations were averaged with $V_{\mathrm{f}}$ values.

f. Resulting maps were further averaged with $V_{\mathrm{f}}$ values (six in total for Bucharest: three for the worst-case model and the three traffic scenarios and three for Monte Carl-averaged scenario results) for a final result map, revealing the combined index of vulnerable accessibility (Fig. 7).

By merging polygons representing areas which can become inaccessible after an earthquake (for each simulation) and also accounting for the number of times these polygons are generated, a very useful representation of areas difficult to reach can be generated. After reclassification (in our case based on five equal intervals), a qualitative probability for areas to become inaccessible can be expressed. Areas with 
Table 2. Parameters used for of Bucharest post-earthquake road network risk analysis.

\begin{tabular}{|c|c|c|c|}
\hline Facilities & Analysis parameters & Considered scenarios & Number of maps resulting \\
\hline Emergency hospitals & $\begin{array}{l}\text { Analysis type: service area } \\
\text { - impedance attributes: } \\
\text { minutes (depending on traffic scenario) } \\
\text { - default breaks: } 5,10 \ldots 60 \mathrm{~min} \\
\text { scenarios and the worst-case } \\
\text { - no one-way restrictions } \\
\text { - travel from facility } \\
\text { - restrictions: polygon barriers } \\
\text { (inaccessible areas provided } \\
\text { by identifying holes from } \\
\text { initial service area analysis } \\
\text { using the "obstruction" }\end{array}$ & $\begin{array}{l}\text { For three traffic scenarios } \\
(02: 00,08: 00 \text { and 18:00 LT) } \\
\text { - pre- and post-earthquake, } \\
\text { considering } 20 \text { Monte Carlo } \\
\text { and second-best times for } \\
\text { model (failure of all listed } \\
\text { segments) for blocked roads and } \\
\text { bridges } \\
\text { For our worst-case simulations we } \\
\text { made a custom selection of vulnerable } \\
\text { bridges based on their health } \\
\text { condition, year of construction }\end{array}$ & $\begin{array}{l}3 \text { (pre-earthquake) }+9 \text { (post- } \\
\text { earthquake }- \text { worst-case model, } \\
\text { including analysis of facilities } \\
\text { which provide the best } \\
\text { intervention) }+20 \text { (post- } \\
\text { earthquake, Monte Carlo } \\
\text { scenarios) }+3 \text { (post- } \\
\text { earthquake, Monte Carlo }\end{array}$ \\
\hline $\begin{array}{l}\text { Emergency hospitals } \\
\text { in category I of } \\
\text { importance (since } \\
\text { they have the main } \\
\text { capacity and } \\
\text { responsibilities in } \\
\text { the case of an } \\
\text { earthquake) }\end{array}$ & $\begin{array}{l}\text { column as impedance attribute } \\
\text { - module currently provided in the } \\
\text { Network-risk toolbox) }\end{array}$ & and length. & $3+9+20+3$ \\
\hline Fire stations & & & $3+9+20+3$ \\
\hline $\begin{array}{l}\text { Origin-destination } \\
\text { pairs for } \\
\text { representative } \\
\text { economic transit } \\
\text { routes }\end{array}$ & $\begin{array}{l}\text { Analysis type: closest facility } \\
\text { - impedance: minutes } \\
\text { (depending on traffic } \\
\text { scenario); } \\
\text { - Facilities to find: the total } \\
\text { number of origins/destinations } \\
\text { (to be able to extract not just } \\
\text { the statistics as with cost } \\
\text { Matrix analysis, but also the } \\
\text { path of the route). } \\
\text { - accumulators: minutes } \\
\text { (depending on traffic } \\
\text { scenario) and meters; } \\
\text { - analysis was performed also } \\
\text { by changing initial origins } \\
\text { within destinations (to show } \\
\text { differences due to traffic ways } \\
\text { and one-way restrictions). }\end{array}$ & $\begin{array}{l}\text { For three traffic scenarios } \\
(02: 00,08: 00 \text { and 18:00 LT) } \\
\text { - pre- and post-earthquake }\end{array}$ & $\begin{array}{l}3 \text { (pre-earthquake) }+3 \text { (post- } \\
\text { earthquake - worst-case } \\
\text { scenario) } \\
+3 \text { time difference tables }\end{array}$ \\
\hline
\end{tabular}

the lowest probability are generated just for the worst-case model, not appearing during the Monte Carlo-limited number of simulations (Fig. 8).

A different product which can be obtained using the network database and closest-facility analysis is maps showing relations between emergency hospitals or fire stations (as destinations) and high-risk buildings (as origins) to determine the routes or best facilities in terms of safety that are in proximity. Useful maps or routing services which could become available in near-real time can be obtained by combining the fastest routes for OD pairs, for a given scenario, showing also which roads are vital in an emergency situation (that need to remain functional, since they are critical, providing the quickest access time in the origin).
The seismic risk due to road network dysfunctionalities can be expressed not just by considering the impact of road blockage and traffic on emergency intervention, leading to time limitations in reaching patients. When roads are closed, connectivity throughout the city can be lost for days, weeks or years, with a high impact on the economy - due to delays in stock supplies and production, greater costs for fuel, or loss of clients. Our network dataset can also be used to monitor the differences between pre- and post-earthquake travel times for representative OD pairs. For this case study we selected eight pairs in relevant cardinal points, some with links to the city center and some aiming to show if in the case of an earthquake the initially preferred route throughout the city changes in favor of the external ring road. 
Table 3. Reclassification intervals for service area polygons.

\begin{tabular}{lr}
\hline Default breaks for service areas & $\begin{array}{r}\text { Reclassification } \\
\text { values }\left(V_{\mathbf{r}}\right)\end{array}$ \\
\hline$\leq 10 \mathrm{~min}$ & 1 \\
\hline $10-15 \mathrm{~min}$ & 2 \\
\hline $15-20 \mathrm{~min}$ & 3 \\
\hline $20-30 \mathrm{~min}$ & 4 \\
\hline$>30$ min, chosen to correspond \\
$\begin{array}{l}\text { to the golden-hour-of-medicine } \\
\text { principle }- \text { Lerner and Moscatti } \\
\text { (2001), given also the necessary }\end{array}$ \\
\begin{tabular}{l} 
round trip \\
\hline
\end{tabular}
\end{tabular}

Uncertainties and limitations are an important aspect to account for. As a preliminary evaluation we provide the following qualitative uncertainty evaluation:

- The road network dataset accuracy is a small source of uncertainty.

- The limited dataset regarding buildings which could collapse during an earthquake is a moderate source of uncertainty.

- Limitation in evaluating and validating the travel times for emergency intervention vehicles (as recently the allowance of using tramway-separated tracks led to improved intervention times) is a moderate source of uncertainty.

- The typical traffic scenarios considered are a small source of uncertainty.

- Post-earthquake traffic patterns are a big source of uncertainty.

\subsection{Results}

The figures presented in this section summarize our main findings and are obtained for the multiple Monte Carlo and worst-case scenario run with the Network-risk toolbox. Results are believed to contribute to the following:

- operational procedures of the Inspectorates for Emergency Situations (such as the National Concept for PostEarthquake Intervention - implementation discussion ongoing),

- risk-reduction strategies elaborated at the national and local level,

- the planning of new emergency hospitals in Bucharest,
- the identification of easy-to-access locations for emergency containers.

Figure $5 \mathrm{a}$ and $\mathrm{b}$ reflect differences between the worst-case scenario (all roads and bridges with a probability of damage affected) and results from Monte Carlo simulations. As such, Fig. 5a presents, for some areas, slightly more increased intervention time values. Figure $5 \mathrm{c}$ shows service area intervals when considering only emergency hospitals in category I of importance. It can be seen that their distribution is generally satisfactory; however there is an area with significantly greater intervention times, reflected also by Fig. 5a and b, in the southwest of Bucharest (Rahova and Ferentari neighborhoods) - an area known also for its socioeconomic vulnerability (Armas et al., 2016), also with no major hospital in proximity. Due to the significant damage expected in the central area, intervention times are expected to be considerable (given also the traffic values for the considered scenario). The impact of a central hospital such as Coltea is reflected in the partial decrease in ambulance intervention times for the city center. However, in the post-earthquake chaos, especially if the earthquake strikes at rush hour, traffic jams are going to pose a considerable threat to road accessibility; our study reveals some of these effects (Figs. 5-9) and that some areas could be accessed much easier by ambulances from non-central locations. Bridge dysfunctionalities do not seem to pose great influences (when comparing also with no damaged bridge scenarios), since in general there are many nearby alternatives. The Basarab Overpass (northwest of the center - labeled in Fig. 3) is the only bridge that, if inaccessible, could lead to a considerable increase in intervention times. Figure 5d is, although difficult to comprehend at first sight, important, since it provides a visual check upon the correlations between minimum intervention times and the number of hospitals that provide this time; if an area is green and is also hatched, this means that the area is close to multiple emergency hospitals, having lower vulnerability in case of medical emergencies. Data behind this type of map add additional understanding to the overall accessibility analysis, being, however, more demanding in their creation (requiring service area analysis per facility and counting of the number of overlapping polygons with a certain value).

Figure 6 shows service area results for fire stations; the distribution of fire stations is more symmetrical in Bucharest than the distribution of hospitals, also with a unit in the city center ("Mihai Vodă" fire department), behind the Bucharest City Hall building. For the chosen scenario (typical traffic for Monday at 08:00 LT), the influence of this distribution can be seen south of Piata Unirii (Fig. 6b, zoomed-in map), where also boulevards are not expected to be blocked by debris, but to the north - toward Piața Universității and Piața Romană post-earthquake congestion and road segment blockages are expected to significantly increase the travel times. To help in the effort of reducing the intervention times in the central area, the "Victoria Palace" fire department (devoted to the 

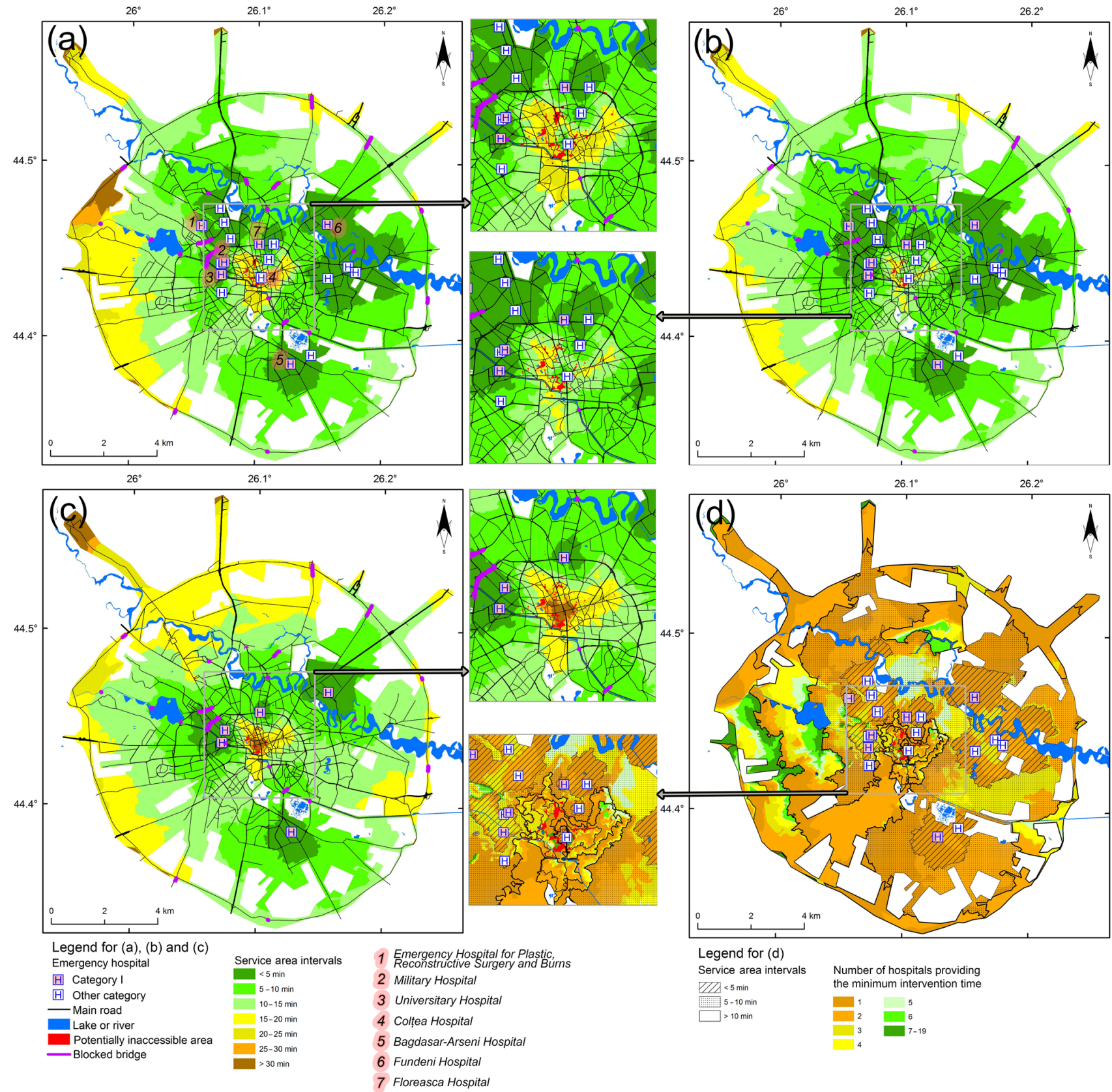

Figure 5. Service areas for emergency hospitals for the typical traffic scenario on Monday at 08:00 LT and for (a) the worst-case model, (b) a Monte Carlo scenario, (c) emergency hospitals in category I of importance and the worst-case model, and (d) the number of emergency hospitals providing the minimum intervention time in the worst-case model. (Datasource: (C) OpenStreetMap contributors 2019. Distributed under a Creative Commons BY-SA License; data from September 2016.) Panel (a) also shows the labels of emergency hospitals in category I of importance and the Coltea Hospital in the city center.

government's building) could contribute; however we did not find considering it in the analysis to be appropriate at the time, until learning more about its characteristics.

In order to facilitate the understanding of results also from the point of view of non-experts, we further show the results of the aggregation methodology used for creating a final in- dex of vulnerable-road accessibility for Bucharest. Figure 7 shows the first map of this kind for the entire territory of Bucharest, reflecting some of the expected features: high vulnerability of accessibility in the central area of the city due to vulnerable buildings and difficult-to-reach (in the case of an earthquake) hospitals (especially in category I of importance) 
Table 4. Formulas for calculating the index for reclassified vulnerability $\left(V_{\mathrm{i}}\right) ; C_{1}$ intervals are relative to the facility database and study area characteristics.

\begin{tabular}{ll}
\hline Formula for $V_{\mathrm{i}}$ & Conditions - depending on $C_{1}$ values \\
\hline$V_{\mathrm{i}}=V_{\mathrm{r}}-0.5$ & $\begin{array}{l}\text { if } C_{1}>=5 \text { for emergency hospitals and fire stations } \\
\text { if } C_{1}>=3 \text { for emergency hospitals in category I of importance }\end{array}$ \\
\hline $\begin{array}{l}V_{\mathrm{i}}=V_{\mathrm{r}} \text { (applied } \\
\text { also to scenarios } \\
\text { without calculated }\end{array}$ & $\begin{array}{l}\text { if } 2<=C_{1}<5 \text { for emergency hospitals and fire stations } \\
C_{1} \text { values) }\end{array}$ \\
\hline$V_{\mathrm{i}}=V_{\mathrm{r}}+0.5$ & $\begin{array}{l}\text { if } C_{1}<2 \text { for emergency hospitals and fire stations } \\
\text { if } C_{1}<2 \text { for emergency hospitals in category I of importance }\end{array}$ \\
\hline
\end{tabular}
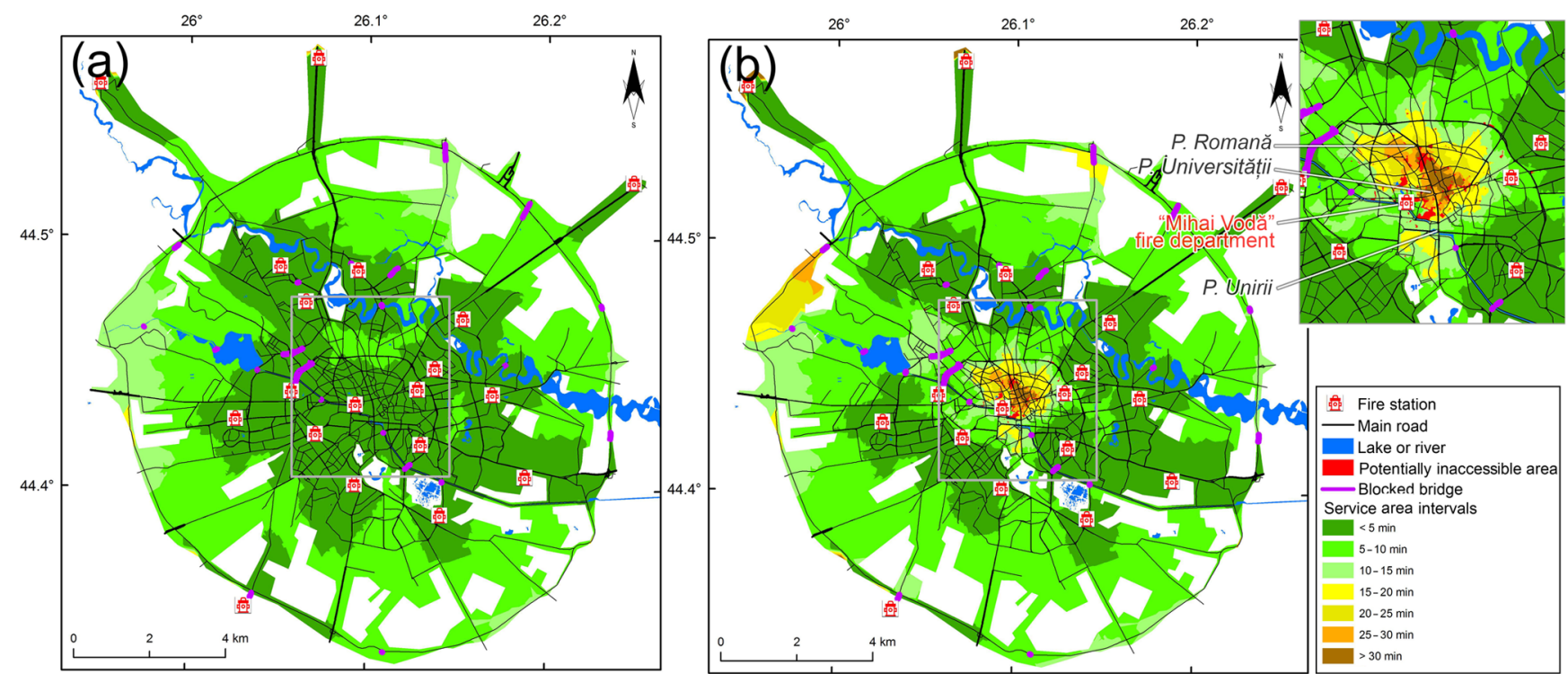

Figure 6. Service areas for fire stations, (a) pre-earthquake and (b) post-earthquake, considering the worst-case model, for the typical traffic scenario on Monday at 08:00 LT. (Datasource: () OpenStreetMap contributors 2019. Distributed under a Creative Commons BY-SA License; data from September 2016.)

and fire stations. Also, the figure shows other areas more difficult to reach by all types of emergency vehicles right after an earthquake: western Bucharest (Militari neighborhood) or southwestern and southeastern Bucharest. Areas with good accessibility appear to be in the inner green belt to the north of the inner ring road - where there are hospitals and fire stations nearby and no disruptive traffic (although it is quite intense during rush hour) and disrupted road segments.

Another important result of the analysis, proving the Network-risk capabilities, is presented in Fig. 8. As expected, inaccessible areas are mostly in the city center (streets such as Blănari, Lipscani, Şelari, Smârdan, Sf. Dumitru, Franceză, Toniţa, Eforiei or Biserica Doamnei), where many buildings are expected to block roads and detour routes to the locations. Other blocked road segments, with lower probability, could be on streets such as Bărăţiei, Pătrašcu Vodă, Vasile Lascăr, Poiana Narciselor, Dr. Vasile Sion, Ion Bre- zoianu, Tudor Arghezi, Batiştei, Jules Michelet, etc. Due to the algorithm for service area computation, some areas between roads are indicated as being blocked (as in Cişmigiu Park for example); however this is a method limitation and can be eliminated through clipping.

Figure 9 is the result of closest-facility analysis, showing the safest and fastest routes (and the density of these routes) between buildings in seismic risk class I and emergency hospitals and which hospitals would be the preferred facility for a certain building, based on proximity (no medical capabilities are considered) - setting premises for better preparedness of hospitals expected to have high patient demand (e.g., medical supplies, hospital beds, doctors). Figure 9a highlights, for the specific scenario, three routes in high demand: from the city center towards the east, west and northwest. Figure $9 \mathrm{~b}$ shows that Coltea Hospital is, despite being in the city center, not the best option for many vulnerable buildings. 

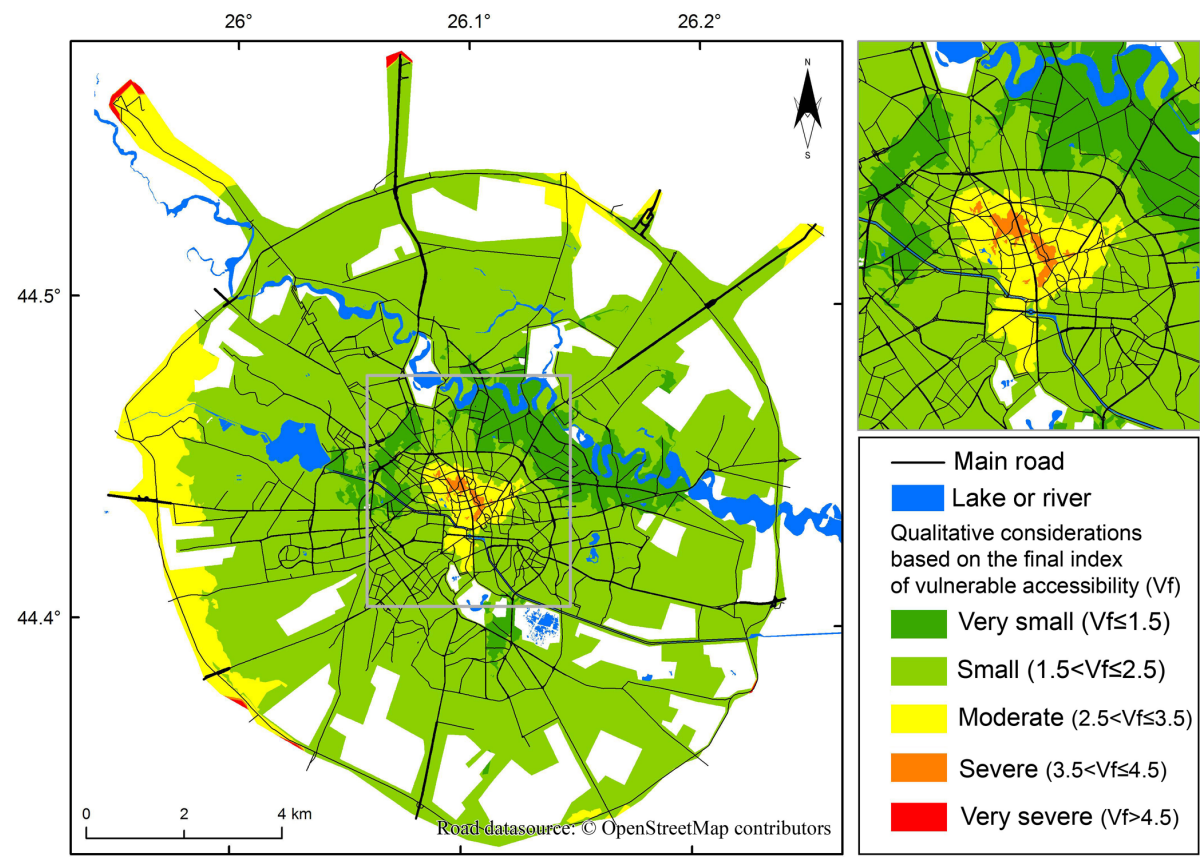

Figure 7. Final map showing qualitative values for the combined final index of vulnerable road network accessibility ( $\left.V_{\mathrm{f}}\right)$ for Bucharest. (Datasource: () OpenStreetMap contributors 2019. Distributed under a Creative Commons BY-SA License; data from September 2016.)

Table 5. Time differences (expressed in minutes) between various OD pairs shown in Fig. 10 and for pre- and post-earthquake conditions.

\begin{tabular}{|c|c|c|c|c|c|c|}
\hline \multirow[t]{2}{*}{ Route } & \multicolumn{3}{|c|}{ From-to (FT) (min) } & \multicolumn{3}{|c|}{ To-from (TF) (min) } \\
\hline & 02:00 LT & 08:00 LT & 18:00 LT & 02:00 LT & 08:00 LT & 18:00 LT \\
\hline Centura-A1 $\rightarrow$ Piața Unirii & 0 & 25 & 19 & 1 & 24 & 21 \\
\hline Piața Unirii $\rightarrow$ Metrou Pantelimon & 0 & 11 & 14 & 0 & 8 & 10 \\
\hline Centura-Otopeni $\rightarrow$ Piața Universității & 5 & 72 & 77 & 8 & 62 & 63 \\
\hline Piața Universității $\rightarrow$ Centura-Giurgiului & 1 & 30 & 33 & 3 & 45 & 44 \\
\hline Centura-Chitila $\rightarrow$ Centura-Olteniței & 1 & 0 & 0 & 1 & 10 & 0 \\
\hline Drumul Taberei $\rightarrow$ Centura-Splai & 0 & 4 & 5 & 0 & 5 & 4 \\
\hline Centura-Măgurele $\rightarrow$ Grădină Zoologică & 0 & 18 & 7 & 0 & 1 & 9 \\
\hline Eroii Revoluției $\rightarrow$ Spitalul Fundeni & 1 & 6 & 11 & 1 & 6 & 10 \\
\hline
\end{tabular}

Table 5 and Fig. 10 show results for representative OD pairs to the economic transit routes - any other OD pairs can be introduced. For the 02:00 LT traffic scenario, differences are not significant, as post-earthquake traffic is not expected to be a significant problem; however for the 08:00 and 18:00 LT scenarios - especially for routes which need to reach the city center (Piața Universității for example), there are clear values showing a mean travel time increase from $110 \%-120 \%$ to $300 \%-432 \%$ for the CenturaOtopeni $\rightarrow$ Piața Universității route.

\section{Conclusions}

In this paper we presented a new methodology for evaluating direct and indirect implications of natural hazards on the transportation network. This methodology was designed to be generally applicable and adaptive to various types of hazards, networks, or available vulnerability and exposure data. Starting from structural evaluation, the analysis focuses on systemic or functional assessment, expressing furthermore the risk inflicted mainly by connectivity loss. After determining hazard, exposure and vulnerability factors - leading to the definition of the network and the identification of segments which can become unusable (and the probability of this to happen), Monte Carlo simulations can be performed. This enables the creation of multiple scenarios evaluated individually in terms of generated risk (for emergency intervention or socioeconomic aspects) and aggregated into final risk indices. There are also capabilities of accounting for preand post-disaster traffic and for emergency facilities' capacity or equipment. In order to facilitate the use of the method- 


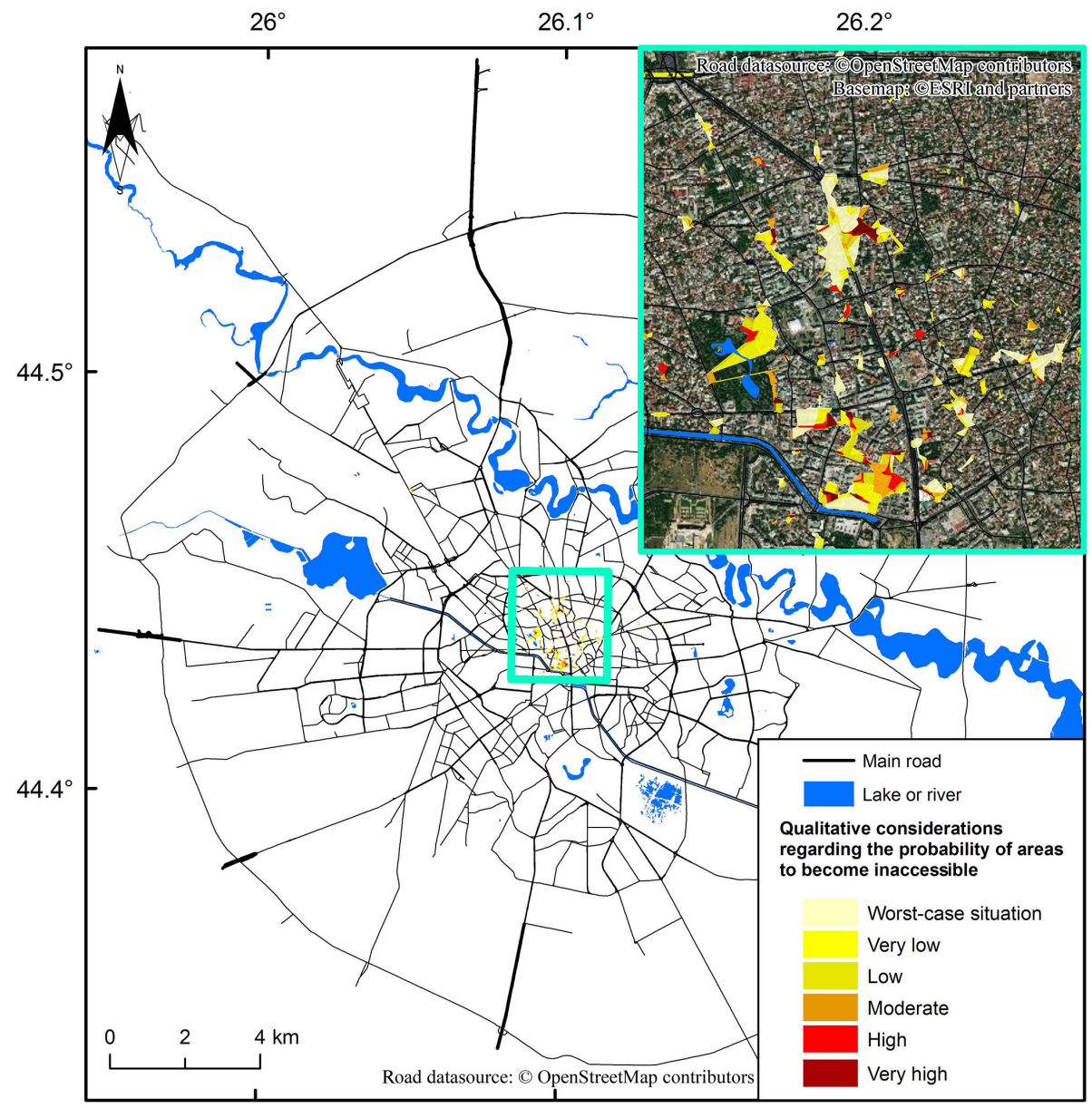

Figure 8. Areas that can become inaccessible immediately after an earthquake. (Datasource: () OpenStreetMap contributors 2019. Distributed under a Creative Commons BY-SA License; data from September 2016. Basemap: (C ESRI and contributors.)

ology we integrated it into an open toolbox (collection of models) entitled Network-risk, which is free to download and customize.

To prove its capabilities, Network-risk was tested on the entire road network of Bucharest, Romania, one of Europe's most endangered capitals due to earthquakes, considering the high seismic-hazard values generated by intermediatedepth Vrancea earthquakes, the vulnerable building stock (349 high- or moderate-rise buildings are categorized as belonging to seismic risk class I in January 2016, representing just the tip of the vulnerability "iceberg") and also major traffic congestion patterns. One of the most difficult parts in the analysis was properly inputting the data collection. As shown, this can be achieved (at least in a preliminary form) in a satisfactory form by using OpenStreetMap data along with a Network-risk module designed to arrange (partially automatically) the network data into the ArcGIS network format. Digitized traffic areas based on Google Traffic layers or empirical formulas, literature fragility functions and expert judgment for determining road segment failure probabilities also contribute to the input. Our analysis focused both on the evaluation of emergency intervention times (for emergency hospitals and fire stations) and on the evaluation of economic implications for representative commercial routes (time delays in post-earthquake conditions).

Results show that the city center would be significantly vulnerable not just because of collapsing buildings but also due to the difficulty of reaching these sites by ambulances and firefighters; although there are facilities nearby, such as the Coltea Hospital (however not of category of importance I) and the Mihai Vodă fire department, these do not provide safe routes to all potentially affected buildings, due to road blockages and traffic jams, considering especially the typical traffic scenarios on Monday at 08:00 and 18:00 LT. Aggregated results in Figs. 7 and 8 show that also for the western, southwestern and southeastern parts of Bucharest, overall intervention times can be significant - a valid supposition confirmed verbally by members in the emergency intervention forces. 

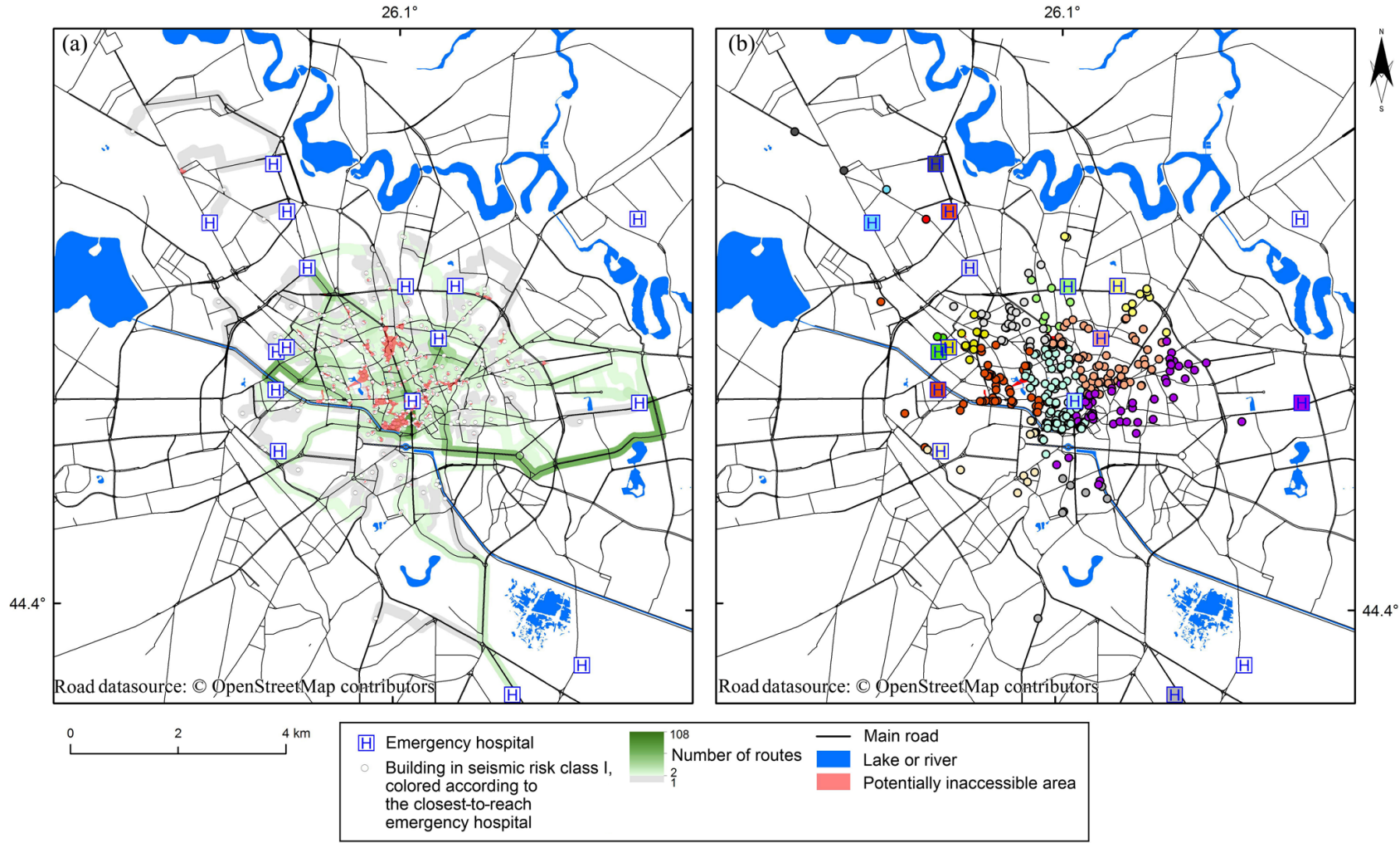

Figure 9. Maps reflecting fastest routes (and the density of these routes) between buildings in seismic risk class I and (a) emergency hospitals and (b) the closest hospital for the typical traffic scenario on Monday at 08:00 LT. (Datasource: () OpenStreetMap contributors 2019. Distributed under a Creative Commons BY-SA License; data from September 2016.)
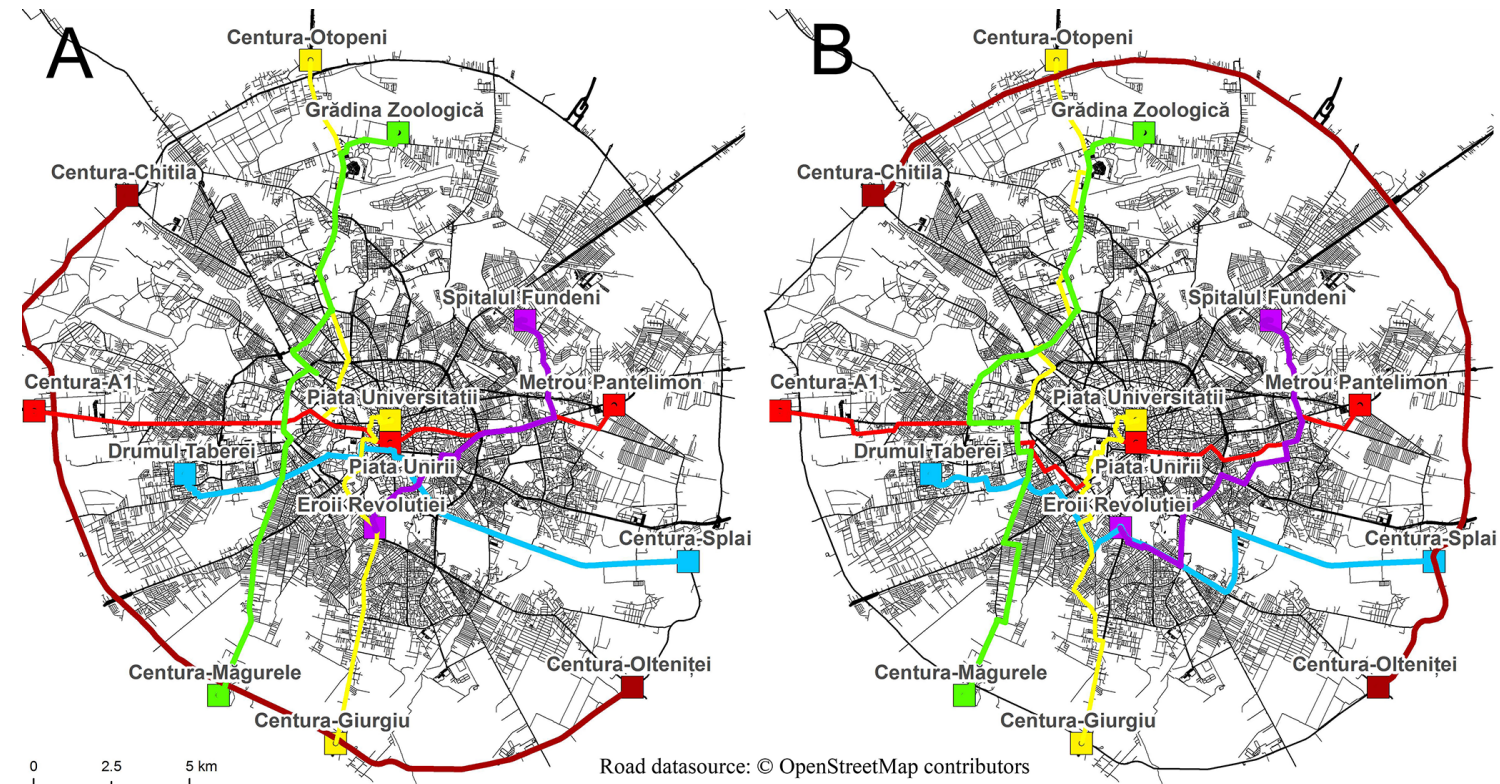

Figure 10. Fastest routes for eight representative OD pairs for Bucharest, for the FT directions, and for the typical traffic scenario on Monday (a) at 02:00 LT and (b) 18:00 LT. (Road datasource: () OpenStreetMap contributors 2019. Distributed under a Creative Commons BY-SA License; data from September 2016.) 


\section{Discussion}

Stakeholders such as emergency situation managers provided us with important feedback, acknowledging that the final products can fit well into their procedures, both for scenario development (prevention) and for near-real-time implementation (reaction). Practical applications can consist of determining new locations for emergency facilities, for increasing facility capacities, for traffic management planning, or for efficient and safer routing of emergency intervention vehicles. As a comment for future methodology users, we want to mention that, when calculating service areas, it is very useful to account for the dependency on a single facility to provide the minimum intervention time, and we will develop a module in Network-risk to provide a performance indicator for this purpose.

In our opinion, the service area analysis for Bucharest shows the necessity of an emergency hospital in the southwestern part of Bucharest - an area also known for its high socioeconomic vulnerability. For the city center, a strategy in the case of an earthquake has to be elaborated and put into place, referring to measures to facilitate and restrict the access in the area in the case of natural disasters, traffic redirection and design of safe road access corridors. As highlighted, the vulnerability of routes connecting the city center, especially with a destination in the north or south, can be significant, with a travel time increase greater than $150 \%$ in typical scenario conditions.

As Network-risk is for now dependent on the commercial software ArcGIS Desktop Advanced, with the Network Analyst extension, we will try in the near future to integrate its methodology also into non-commercial GIS software such as QGIS. However, this still requires, at the moment, more development toward advanced network analysis. The current Network-risk toolbox is under continuous development, and in future versions more features will be available, so please check the website regularly. We also aim to test it more consistently, with analyses at the regional and national scale (using also rapid seismic loss estimations generated by the SeisDaRo system of INFP, presented by TomaDanila et al., 2018), for multiple hazard scenarios and also for more detailed vulnerability datasets comprising also the social behavior and interaction of people with transportation networks.

We hope that this article will provide researchers with important practical guidelines on how to analyze the risks of transportation networks affected by natural hazards and be a useful tool to be applied in other parts of the world and provide stakeholders with an example of useful results which they could benefit from in their efforts to better understand and mitigate risks.
Code and data availability. The Network-risk toolbox for ArcGIS Desktop and sample data for Bucharest (used for this study) can be downloaded, with the user manual, at http://www.infp.ro/index. php?i=nri (last access: 27 April 2020) (Toma-Danila and Tiganescu, 2020). Please revisit the address and check for new versions, since the toolbox is constantly being upgraded.

Author contributions. DTD and IA developed the methodology, and DTD and AT implemented and tested it in GIS, obtaining results analyzed also by IA. DTD prepared the paper, with contributions from all co-authors.

Competing interests. The authors declare that they have no conflict of interest.

Special issue statement. This article is part of the special issue "Natural hazard impacts on technological systems and infrastructures". It is a result of the EGU General Assembly 2019, Vienna, Austria, 7-12 April 2019.

Acknowledgements. This work was financed through the doctoral scholarship of the main author from the University of Bucharest, Faculty of Geography, and partially from the "Seismology and Earthquake Engineering Research Infrastructure Alliance for Europe" (SERA) Project (2017-2020) - EU Horizon 2020 program (grant no. 730900) - and from the "Towards more Earthquakeresilient Urban Societies through a Multi-sensor-based Information System enabling Earthquake Forecasting, Early Warning and Rapid Response actions" (TURNkey) Project (2019-2022) - EU Horizon 2020 program (grant no. 821046).

Financial support. This research has been supported by a doctoral grant from University of Bucharest, Faculty of Geography, the "Seismology and Earthquake Engineering Research Infrastructure Alliance for Europe" (SERA) Project - EU Horizon 2020 program (grant no. 730900) and the "Towards more Earthquake-resilient Urban Societies through a Multi-sensor-based Information System enabling Earthquake Forecasting, Early Warning and Rapid Response actions" (TURNkey) Project - EU Horizon 2020 program (grant no. 821046).

Review statement. This paper was edited by Elena Petrova and reviewed by Mihai Micu and two anonymous referees. 


\section{References}

Adachi, T. and Ellingwood, B. R.: Service ability of earthquakedamaged water systems: effects of electrical power availability and power back up systems on system vulnerability, Reliab. Eng. Syst. Safe., 93, 78-88, 2008.

Argyroudis, S. A., Pitilakis, K. D., and Anastasiadis, A. I.: Roadway network seismic risk analysis in urban areas: the case of Thessaloniki - Greece, in: Proceedings of the Geoline Conference, Lyon, France, 2005.

Armas, I., Ionescu, R., Gavris, A., and Toma-Danila, D.: Identifying seismic vulnerability hotspots in Bucharest, Appl. Geogr., 77, 49-63, 2016.

Asaithambi, G. and Basheer, S.: Analysis and Modeling of Vehicle Following Behavior in Mixed Traffic Conditions, Transp. Res. Proc., 25, 5094-5103, 2017.

Bast, H., Delling, D., Glodberg, A., Muller-Hannemann, M., Pajor, T., Sanders, P., Wagner, D., and Werneck, R. F.: Route Planning in Transportation Networks, in: Algorithm Engineering, edited by: Kliemann, L. and Sanders, P., Springer, Cham, 19-80, 2016.

Bono, F. and Gutierrez, E.: A network-based analysis of the impact of structural damage on urban accessibility following a disaster: the case of the seismically damaged Port Au Prince and Carrefour urban road networks, J. Transp. Geogr., 19, 1443-1455, 2011.

Burt, J. M. and Garman, M. B.: Conditional Monte Carlo: A Simulation Technique for Stochastic Network Analysis, Manage. Sci., 18, 207-217, 1971.

Caiado, G., Oliveira, C., Ferreira, M. A., and Sa, F.: Assessing urban road network seismic vulnerability: an integrated approach, in: Proceedings of the 15th WCEE, Lisbon, Portugal, 2012.

Chang, L., Elnashai, A. S., and Spencer Jr., B.: Post-earthquake modelling of transportation networks, Struct. Infrastruct. Eng., 8, 893-911, 2012.

Coburn, A. and Spence, E.: Earthquake Protection, Wiley, Hoboken, 2002.

Costa, J. L. D.: Standard Methods for Seismic Analyses, Byg Rapport No. r-064, Danmarks Tekniske Universitet, available at: http://www.byg.dtu.dk/publications/rapporter/r-064.pdf (last access: 15 May 2020), 2003.

Crowley, H., Colombi, M., Silva, V., Monteiro, R., Ozcebe, S., Fardis, M., Tsionis, G., and Askouni, P.: Fragility functions for roadway bridges, D3.6 of the SYNER-G Project, available at: http://www.vce.at/SYNER-G/files/dissemination/ deliverables.html (last access: 15 May 2020), 2011.

Douglas, J., Serrano, J. J., Comte, J., Bouc, O., Arnal, C., Robida, F., Modaressi, H., Logtmeijer, C., Vowles, G., and Holt, I.: Risk assessment for the road network in the French-Italian border region using web services, in: Proceedings of the 17th IIASA-DPRI forum on integrated disaster risk management, Stresa, Italy, 2007.

Fleischhauer, M.: The role of spatial planning in strengthening urban resilience, in: Resilience of cities to terrorist and other threats, edited by: Kirillov, I. A. and Pasman, H. J., Springer, Berlin, 273-298, 2008.

Franchin, P., Lupoi, A., and Pinto, P. E.: On the role of road networks in reducing human losses after earthquakes, J. Earthq. Eng., 10, 195-206, 2006.

Franchin, P., Cavalieri, F., Pinto, P. Lupoi, A., Vanzi, I., Gehl, P., Kazai, B., Weatherhill, G., Esposito, S., and Kakderi, K.: General methodology for systemic vulnerability assessment, D2.1 of the
SYNER-G Project, available at: http://www.vce.at/SYNER-G/ files/dissemination/deliverables.html (last access: 15 May 2020), 2011.

Georgescu, E. S. and Pomonis, A.: New Archival Evidence on the 1977 Vrancea, Romania Earthquake and Its Impact on Disaster Management and Seismic Risk, in: Seismic Hazard and Risk Assessment, Springer Natural Hazards, edited by: Vacareanu, R. and Ionescu, C., Springer, Cham, 281-295, 2018.

Goncharov, S. F.: Medical consequences of earthquake disasters in Russia; Earthquake and People's Health, in: Proceedings of the WHO Symposium, Kobe, Japan, 1997.

Graser, A., Straub, M., and Dragaschnig, M.: Is OSM Good Enough for Vehicle Routing? A Study Comparing Street Networks in Vienna, in: Progress in Location-Based Services, edited by: Gartner, G. and Huang, H., Springer, Cham, 3-17, 2014.

$\mathrm{Gu}$, D.: Exposure and vulnerability to natural disasters for world's cities; United Nations Department of Economic and Social Affairs, Population Division, Technical Paper No. 2019/4, Population Division, Department of Economic and Social Affairs, New York, 2019.

Hackl, J., Lam, J. C., Heitzler, M., Adey, B. T., and Hurni, L.: Estimating network related risks: A methodology and an application in the transport sector, Nat. Hazards Earth Syst. Sci., 18, 2273 2293, https://doi.org/10.5194/nhess-18-2273-2018, 2018.

Hekimoglu, Y., Melez, I. E., Canturk, G., Erkol, Z., Canturk, N., Dizdar, M. G., Melez, D. O., Guler, O. S.: Evaluation of the deaths secondary to entrapment under the debris in the Van earthquake, Egypt. J. Forens. Sci., 3, 44-47, 2013.

Ianoş, I., Merciu, G.-L., Merciu, C., and Pomeroy, G.: Mapping Accessibility in the Historic Urban Center of Bucharest for Earthquake Hazard Response, Nat. Hazards Earth Syst. Sci. Discuss., https://doi.org/10.5194/nhess-2017-13, 2017.

Jenelius, E. and Mattsson, L. G.: Road network vulnerability analysis: Conceptualization, implementation and application, Comput. Environ. Urban, 49, 136-147, 2015.

Karduni, A., Kermanshah, A., and Derrible, S.: A protocol to convert spatial polyline data to network formats and applications to world urban road networks, Sci. Data, 3, 160046, https://doi.org/10.1038/sdata.2016.46, 2016.

Kiremidjian, A., Moore, J., Fan, Y. Y., Yazlali, O., Basoz, N., and Wiliams, M.: Seismic Risk Assessment of Transportation Network Systems, J. Earthq. Eng., 11, 371-382, 2007.

Koks, E. E., Rozenberg, J., Zorn, C., Tariverdi, M., Vousdoukas, M., Fraser, S. A., Hall, J. W., and Hallegatte, S.: A global multihazard risk analysis of road and railway infrastructure assets, Nat. Commun., 10, 2677, https://doi.org/10.1038/s41467-01910442-3, 2019.

Lerner, E. B.,= and Moscati, R. M.: The Golden Hour: Scientific Fact or Medical "Urban Legend”?, Acad. Emerg. Med., 8, 758760, 2001.

Marica, I.: Report on 2015 Bucharest club tragedy unveils healthcare system problems, available at: https://www.romania-insider. com/report-2015-colectiv-club-tragedy (last access: 1 December 2019), 2017.

Marmureanu, G., Cioflan, C. O., and Marmureanu, A.: Researches on local seismic hazard (Microzonation) for metropolitan Bucharest area, Tehnopress, Iasi, Romania, 2010. 
Miller, M. K.: Seismic Risk Assessment of Complex Transportation Networks, PhD thesis, Stanford University, Stanford, USA, 2014.

Moroux, P., Bertrand, E., Bour, M., LeBrun, B., Depinois, S., Masure, P., and Risk-UE team: The European Risk-UE Project: An advanced approach to earthquake risk scenarios, in: Proceedings of the 13th WCEE, Vancouver, Canada, 2004.

Munigety, C. R. and Mathew, T. V.: Towards Behavioral Modeling of Drivers in Mixed Traffic Conditions, Transp. Dev. Econ., 2, 6, https://doi.org/10.1007/s40890-016-0012-y, 2016.

Neagu, C., Arion, C., Aldea, A., Calarasu, E. A., Vacareanu, R., and Pavel, F.: Ground Types for Seismic Design in Romania, in: Seismic Hazard and Risk Assessment, Springer Natural Hazards, edited by: Vacareanu, R. and Ionescu, C., Springer, Cham, 157172,2018

NIS - National Institute of Statistics: TEMPO-Online database, available at: http://statistici.insse.ro:8077/tempo-online/ (last access: 1 December 2019), 2018.

Pavel, F.: Next Future Large Earthquake in Romania: A Disaster Waiting to Happen?, Seismol. Res. Lett., 88, 1-3, 2016.

Pavel, F. and Vacareanu, R.: Scenario-based earthquake risk assessment for Bucharest, Romania, Int. J. Disast. Risk Reduct., 20, 138-144, 2016.

Pesaresi, M., Ehrlich, D., Kemper, T., Siragusa, A., Florczyk, A., Freire, S., and Corban, C.: Atlas of the Human Planet 2017: Global Exposure to Natural Hazards, Publications Office of the European Union, Ispra, Italy, https://doi.org/10.2760/19837, 2017.

Pinto, P. E., Cavalieri, F., Franchin, P., and Lupoi, A.: Systemic vulnerability and loss for transportation systems, D5.5 of the SYNER-G Project, available at: http://www.vce.at/SYNER-G/ files/dissemination/deliverables.html (last access: 15 May 2020), 2012.

Pitilakis, K. D. and Kakderi, K. G.: Seismic risk assessment and management of lifelines, utilities and infrastructures, in: Proceedings of the 5th ICEGE, Santiago, Chile, 2011.

Poljanšek, K., Bono, F., and Gutiérrez, E.: Seismic risk assessment of interdependent critical infrastructure systems: The case of European gas and electricity networks, Earthq. Eng. Struct. D, 41, 61-79, https://doi.org/10.1002/eqe.1118, 2011.

Santarelli, S., Bernardini, G., and Quagliarini, E.: Earthquake building debris estimation in historic city centres: From real world data to experimental-based criteria, Int. J. Disast. Risk Reduct., 31, 281-291, 2018.

Sartori, M.: Seismic protection of the Basarab overpass in Bucharest, in: Proceedings of the 15th WCEE, Lisboa, Portugal, 2012.
Sevtsuk, A. and Mekonnen, M.: Urban network analysis. A new toolbox for ArcGIS, Rev. Int. Géomatique, 22, 287-305, 2012.

Shahabi, K. and Wilson, J. P.: CASPER: intelligent capacity-aware evacuation routing, Comput. Environ. Urban, 46, 12-24, 2014.

Sniedovich, M.: Dijkstra's algorithm revisited: the dynamic programming connexion, J. Control Cybernet., 35, 599-620, 2006.

Tesfamarian, S. and Goda, K.: Handbook of Seismic Risk Analysis and Management of Civil Infrastructure Systems, Woodhead Publishing, Sawston, Cambridge, UK, 2013.

Toma-Danila, D.: A GIS framework for evaluating the implications of urban road network failure due to earthquakes: Bucharest (Romania) case study, Nat. Hazards, 93, 97-111, 2018.

Toma-Danila, D. and Armas, I.: Insights into the possible seismic damage of residential buildings in Bucharest, Romania, at neighborhood resolution, Bull. Earth Eng., 15, 1161-1184, 2017.

Toma-Danila, D. and Tiganescu, A.: Network-risk toolbox for ArcGIS User Manual, 2020, available at: http://www.infp.ro/index. php?i=nri, last access: 15 May 2020.

Toma-Danila, D., Armas, I., and Cioflan, C. O.: Conceptual framework for the seismic risk evaluation of transportation networks in Romania, in: The 1940 Vrancea Earthquake, Issues, Insights and Lessons Learnt. Proceedings of the Symposium Commemorating 75 Years from November 10, 1940 Vrancea Earthquake, Springer Natural Hazards Series, edited by: Vacareanu, R. and Ionescu, C., Springer International Publishing, Switzerland, 481-496, 2016.

Toma-Danila, D., Cioflan, C., Ionescu, C., and Tiganescu, A.: The near real-time system for estimating the Seismic Damage in Romania (SeisDaRo) - recent upgrades and results, in: Proceedings of the 16th ECEE, Tessaloniki, Greece, 2018.

TomTom: TomTom traffic index, available at: https://www.tomtom. com/en_gb/trafficindex (last access: 1 December 2019), 2018.

Vodak, R., Bil, M., and Sedonik, J.: Network robustness and random processes, Physica A, 428, 368-382, 2015.

Voumard, J., Derron, M.-H., and Jaboyedoff, M.: Natural hazard events affecting transportation networks in Switzerland from 2012 to 2016, Nat. Hazards Earth Syst. Sci., 18, 2093-2109, https://doi.org/10.5194/nhess-18-2093-2018, 2018.

Wang Y., Siu-Kui, A., and Qiang, F.: Seismic Risk Assessment and Mitigation of Water Supply Systems, Earthq. Spectra, 26, 257274, 2010.

Wilkerson, C.: How much economic damage do large earthquakes cause?, Oklahoma Economist, Oklahoma, USA, 2016.

Zanini, M. A., Faleschini, F., Zampieri, P., Pellegrino, C., Gecchele, F., Gastaldi, M., and Rossi, R.: Post-quake urban road network functionality assessment for seismic emergency management in historical centres, Struct. Infrastruct. Eng., 17, 1117-1129, 2017. 